\title{
Enhancement of carbonate, silicate, and sulfide weathering via fluvial sediment abrasion
}

\author{
ScheIngRoss, J.S. ${ }^{1,2^{*}}$, BufE, A. ${ }^{2}$, Hemingway, J. ${ }^{3}$ \\ HOVIUS, N. ${ }^{2}$, SCHLEICHER, A.M. ${ }^{2}$, GOLDBERG, T. ${ }^{2}$
}

${ }^{1}$ Dept. of Geological Sciences, University of Nevada Reno ${ }^{2}$ Geman Research Center for Geosciences (GFZ), Potsdam

${ }^{3}$ Dept. of Earth and Planetary Sciences, Harvard University

Mineral weathering can influence Earth's climate over geologic timescales and plays an important role in a number of biogeochemical cycles. During source-to-sink transport, weathering is often assumed to occur predominately on hillslopes and in sedimentary deposits where order ky-My residence times of solids can compensate for potentially slow reaction kinetics. However, in active landscapes, high rates of erosion reduce the amount of time minerals spend on hillslopes, allowing the delivery of large volumes of unweatherd sediment to river channels. Rivers may act as hotspots for weathering, as particle abrasion during sediment transport increases mineral surface area and allows for faster reaction rates. However, the influence of fluvial transport on chemical weathering has yet to be quantified. Here, we attempt to quantify how fluvial sediment abrasion increases chemical weathering using hydraulically-scaled annular flume experiments. With 14 experiments, we explored the influence of particle geochemical composition, surface area, and abrasion rate on chemical weathering by varying sediment lithology (shale, basalt, and granite) and size $(<63-3000$ $\mu \mathrm{m})$. Experiments ran continuously for $\sim 50$ days, allowing for $\sim 1000 \mathrm{~km}$ of transport, and we assessed weathering by evaluating changes in the major element composition of the dissolved load through time. Preliminary results separting solutes into contributions from carbonate weathering, silicate weathering, and sulfide oxidation show that sediment abrasion in shale experiments led to a $\sim 3.5$-fold increase in carbonate-derived cation production and a $\sim 2$-fold increase in sulfate production relative to replicate experiments in static tanks without transport. In the basalt experiments, sediment abrasion led to a $\sim 1.5$-fold increase in silicate-derived cation production relative to static tanks, and granite experiments showed no detectable influence of sediment abrasion on weathering. These results provide proof-of-concept evidence for mineralogy-dependent enhancement of weathering due to sediment abrasion and are allowing ongoing work to compare weathering fluxes between in-river and hillslope processes. 